\title{
Talk about values in the British National Health Service
}

\author{
HUW THOMAS ${ }^{1}$ AND STEPHEN PATTISON ${ }^{2}$ \\ (1) Cardiff University, Cardiff, UK (2) University of Birmingham, Birmingham, UK
}

\section{Introduction}

Value judgements and values talk are central to the practices of professions. Most obviously, the politically potent - if sociologically questionable - notion of a profession as a self-regulating occupation that deploys expertise in the public interest has at its core the idea of professionals abiding by a necessarily value-saturated professional code (Johnson 1972). In addition, concepts important to particular professions - such as justice, amenity and health - are ineradicably value-inflected (Thomas 1987). In that way, values-talk is central to professional identity-formation. Given that identity is formed in part through boundary-definition and boundarypolicing, it is clear that professional values-talk is not simply inward-looking. On the contrary, it appears to be used in a variety of ways to attempt to regulate relations with those that professionals come across in their working environments.

Yet professionals do not have a clear field in which to espouse and enact values (Freidson 2001). Public policy - which ultimately sanctions, and can constrain, so much of a profession's authority - will itself be couched in the vocabulary of values, whatever realpolitik may sometimes motivate individual interventions or policies. The organizations within which the majority of contemporary professional work is conducted - universities, companies, local government offices, hospitals and the like - will themselves have some kind of organizational culture in which values are embedded. So how does the complex interaction of professional, organizational and public policy values work out? And where might all this leave the values and commitments of individual professionals, who will have been socialized by family and community long before they become professionals (Hoggett et al. 2009)?
Healthcare provides an intriguing area in which to examine some of these questions. In modern societies, the practices involved in the delivery of healthcare are in large measure outcomes of complex negotiation and struggle between governments claiming rights to enact political values, many kinds of professionals (often as wary of each other as they are of government), powerful commercial interests espousing the values of the market place, and some of the more organized and socially powerful users of healthcare services. Values-talk is typically central to these interactions, and prominently so when serious changes in power-relations are in the offing.

For example, in the age of internet access professionals' technical knowledge does not guarantee the acquiescence of service users to their judgements (Laing et al. 2005a). The phenomenon of internet searching for information and self-diagnosis is becoming more common in relation to health issues (Laing et al. 2005b). One of the more potent triggers for challenges to professional authority is users' concerns over values embedded in the professional-user relationship, and it is this radical value dissonance that can stymie the attempts of professionals to co-opt now-knowledgeable users into accepting professional framing of problems (Newholm et al. 2006). The refusal of some patients to bend to professional power as expressed in professional disparagement of alternative/complementary therapies, for example, shows the way that values-talk can help patients develop and defend an alternative framework to that of the medical profession.

\section{Values talk in health-care}

Cohen (1999) offers a rather different framework for interpreting the significance of values in healthcare.

\section{eevinoxonline}


For her, the healthcare encounter is an engagement of people which inevitably has implications for the moral development of everyone concerned, professionals as well as patients. For someone with her perspective, the word 'care' is not a bureaucratic term, nor is its use accidental: it is a word which describes a particular kind of relationship, a relationship in which are embedded certain kinds of values (e.g., it is a relationship inconsistent with seeing a patient as simply a kind of biological machine, or a nuisance, or a 'bed-blocker'). A caring relationship reinforces the wholeness/integrity of the patient, and also that of the carer. It is, therefore, a good thing for people. Even if it were conceded that a professional could simulate a truly caring attitude so that patients were none the wiser (a pretty unlikely state of affairs in reality), Cohen would regard the professional's personality and moral development as damaged by the simulation.

Cohen has practised within the UK's National Health Service (NHS). This enormous multiprofessional organization - established as a flagship political project in the late 1940s and regularly reformed and reviewed in part or whole ever since - provides a useful focus for starting to analyse the contemporary significance of values-talk. For decades the NHS managed without much talk about values. In recent years such values-talk has become ubiquitous in public (and, one suspects, private) discussions of healthcare (Klein 2007).

There can be little doubt that much of the talk about values in the NHS over the last few decades has been prompted by attempts drastically to change many of its structures and working practices. These changes have taken place within a fraught, and often polarized, socio-political context, as Keynesian orthodoxy in political economy has been challenged by neo-liberalism (Edgar 2010). In these kinds of transformations, theory and practice are intimately connected and struggles in the workplaces of public services like the NHS have been a front-line of (essentially political) struggle.

There is disagreement about the significance of such values-talk. Commentators such as Klein (2007) regard it as of decidedly secondary importance compared to changes in practice. On this view, in healthcare it is actions that count, and patients are not concerned about motives and values - they just want to get well, and be treated well. The talk about values may have some tactical use in struggles over change (e.g., in garnering public, or political, support), but it is physical and behavioural outcomes that ultimately matter.
In this context, what might this change in values talk signify? What kind of work does such talk accomplish (or attempt)? More specifically, how does talk of values relate to the reconfiguration of professional roles that has been part and parcel of the organisational ferment in the NHS for twenty years or more.

Definitive answers to such questions are a way off. Even the outlines of an appropriate research programme remain hazy, though some pointers exist to the detailed ethnographic, discourse-analytic and philosophical research that will be needed (Thomas and Pattison 2010). Yet discussions of values and values-talk need not be conducted entirely without any empirical foundation. In this piece we draw on material derived from case studies of different professions and their interactions with values in the changing NHS. These form a basis for a series of propositions about the role of values-talk in the NHS in its constituent professions, now and in the future. They can therefore be regarded as an agenda of informed hypotheses which might in future be tested by multi-disciplinary/multi-method research. As such, they are staging posts in an emerging understanding of values, and of values-talk, in professional life.

\section{Learning from case studies}

For the last decade, a group of interdisciplinary, interprofessional researchers has been considering the place of values in professional life and public organizations. Two edited books have eventuated from this collaboration. The first, Values in Professional Practice (Pattison and Pill 2004) looked at some of the roles that values play in widely different professional groups from the law and leisure management to nursing and medicine. In the second, Emerging Values in Healthcare (Pattison et al. 2010), contributors look specifically at the history, nature, function and future of values in the British NHS over the last 40 years, relating this directly to particular healthcare professions. The professions examined include, medicine (especially general practice), mental health nursing, general nursing, genetic counselling, pharmacy, chaplaincy and healthcare management. We will draw on the case studies presented there to highlight some general areas of research and enquiry for wider consideration.

\section{equinoxonline}




\subsection{Values and change}

The first, and perhaps most obvious emergent finding is that concern with values, and values-talk in general, becomes most prominent and urgent in times of crisis and change. For most of its 60-year history, for example, the NHS had no formal statement of values. Only in 2009, with the gradual pluralization and diffusion of services across the four nations (England, Wales, Scotland and Northern Ireland) and private as well as public providers entering the provision of care did it seem necessary to create a clear, explicit statement of values within a formal Constitution (DoH 2009). Similarly, for many years, healthcare professions seemed to understand themselves and their functions very well - a stability signified in unchanging professional foundation documents and codes - or even none. Thus pharmacists have only just got round to producing a professional code that embodies a set of values (Badcott 2010), while the nursing profession has iterated several versions of its code of ethics and practice in the last decade alone. Even clergy, in the form of healthcare chaplains, are now asking fundamental questions about their own value, identity and function. It seems that healthcare professions generally are under considerable pressure to change and respond to new challenges in healthcare organization and delivery with increased flexibility and public accountability. This is reflected in far more, and far more conscious, talk about values and principles that help to define the unique and generic contributions and identities of those professionals. It is, then, perhaps no accident that a somewhat beleaguered and fragmented NHS has now itself produced a set of official values in the context of the new NHS Constitution. Here again, the emergence of overt values-talk can be seen as a response to change, crisis in identity and purpose being brought into question so that it needs to be defined and stabilized to ensure future relevance and validity.

\subsection{The content and context of values-talk}

If values matter, then so does creating opportunities for serious talk about them - one of Cohen's (1999) concerns about changes in the NHS in the 1990s is that they were downplaying the importance of, and squeezing out opportunities for, inter-professional care teams to talk about the value-basis of disagreements in their approaches to care of specific patients. But it appears that there may be differences between different areas of healthcare.
It should certainly not be assumed that all professions and organizations talk about the same values, talk about values in the same way, or give the same level of attention to overt values-talk. Content and context can vary enormously.

An instructive example here is the contrast between mental health nursing, which has very consciously tried to engineer its own significance and professional importance by the extensive and overt use of values-talk over the last few decades, against general nursing which seems to have had less resort to explicit values talk (Hannigan 2010; Sellman 2010). Hannigan (2010) in his study of the rise of modern mental health nursing shows how the profession deliberately set out to identify and promulgate clear values that would help to establish its credibility and legitimacy. This was reflected in a review of the profession by the Chief Nursing Officer for England whose 2006 report was entitled, From Values to Action (DoH 2006). No such similar document has ever been produced in relation to the more dominant and numerous profession of general nursing where governing values can perhaps be more tacitly assumed. Professions that are older and perhaps more complacent about their identities and value, such as medicine and chaplaincy, seem to have been relative latecomers to talk around the values table (Ballard 2010; Pill 2010), while a relatively new group such as healthcare managers, introduced in 1983, may have a much clearer understanding if not articulation of the importance of certain values (Pattison and McKeown 2010).

Cohen (1999) was concerned about a decline in opportunities for serious discussion of values in neonatal care. More recently, Pill (2010) has argued that the General Practice branch of the medical profession is quite possibly in a silent process of fragmentation as its practitioners fall - without much comment or discussion - into different camps in terms of their value-orientation towards their work. In mental health nursing, on the other hand, there is some evidence that professional practice is still seen as embodying values which have needed to be argued for and are thus, in turn, contestable. Hannigan (2010) argues that it is not only in team meetings and small groups that discussions of values may take place; in mental health nursing, government inquiries have sometimes provided opportunities for very public and widely shared discussions of important principles and values. Among NHS managers, on the other hand, there appears to be less practice in talking about values (Pattison and McKeown 2010). Moreover, among managers there is perhaps a tendency to think

\section{equinoxonline}


of espoused values as a relatively firmly fixed basis for consensus and shared action, rather than as an arena for discussion and disagreement through which mutual enlightenment and moral development might be possible.

\subsection{Professional identity and boundary marking}

An important implication of the foregoing points is that values and values-talk are often bound up with professional identity and boundary marking. Where values are being defined, invoked and defended, professional identity is probably being contested and boundaries may be being re-affirmed or re-defined. In the case of contemporary pharmacy, for example, the profession is being required to meet new demands for engagement with the NHS and local communities, while at the same time knitting together pharmacy professionals in industry, NHS employment, and in local shop practices. It is in this context, and only very recently, that the Royal Pharmaceutical Society of Great Britain has published its first Code of Ethics (Royal Pharmaceutical Society 2007) that begins to outline and adumbrate the values and virtues by which all pharmacists may be judged (Badcott 2010). In the midst of constant organizational change and with continual demands to make clear what particular skills a profession can offer while at the same time the quest for more generic skills and teamwork is required, it is not surprising that this manifests itself in various kinds of values-talk. At its simplest, this can manifest itself in the adoption of a code or foundation document such as that recently produced by the pharmacy profession. More sophisticated are discussions of values, such as those in hospital chaplaincy, which take account of the values of users of health services, and attempt to find modes of interaction and shared activity which are respectful of diversity of values without sinking to a lowest common denominator (Ballard 2010; Swift 2010).

If values-talk holds out the hope of consensual action, it is also used to mark professional boundaries and hence - paradoxically - increase the work needed to achieve consensual action. Among both pharmacists and hospital chaplains, for example, the need for an appropriate value-stance is tied up with creating professional identities appropriate for a changing NHS (Badcott 2010; Ballard 2010). Chaplains are individually and collectively working out what role if any their personal beliefs and values can have in a health service for a nation which shares no single religious or moral tradition. In these circumstances, goodwill, willingness to communicate about values - what matters - and a kind of moral creativity are vital. Swift (2010) describes the ways in which hospital chaplains of different faiths can work together to help grieving relatives unearth and explore values which they have rarely explicitly addressed and which draw partially and unevenly upon faiths which to the chaplains are unified worldviews. In these circumstances the chaplains are helping individuals realize the values they hold rather than enjoining them to seek comfort in values that the chaplain represents.

\subsection{Responding to the need for teamwork and flexibility}

Strangely, paradoxically even, the values-talk that manifests itself in particular professions may in itself not only represent an attempt better to define what the profession can offer and to secure the identity and functions of its members, but also be a response to the need to engage more fully with other professional groups and parts of the healthcare system. It can be argued that effective teamwork and discussion can only take place between individuals and groups who understand themselves and their own identities and functions. Given the imperative for all healthcare professionals to be patient-centred, and to work together to provide seamless care so that healthcare users do not inadvertently fall through 'cracks' between professionals and institutions, the growth of organizational and intra- and inter-professional values definition and discussion might be seen both as a protection against inappropriate diffusion of professional identity and expertise and also as a means of ensuring that professionals have the confidence to work appropriately with other groups whose roles and principles are equally well-defined and understood. In this way, values-talk can be seen as a solvent of professional boundaries and identities as well as a proclamation of them.

\subsection{The politics of values and values-talk}

Given the potent mixture of change, identity, power and organizational context that we have identified thus far, it perhaps hardly needs to be said that valuestalk is never innocent of power.

Within professions, hierarchies are cemented through acquiescence to value-systems. Monrouxe and Sweeney's (2010) case study of a student General Practitioner's visit to a patient accompanied by his experienced mentor illustrates vividly how the student's tentatively-voiced qualms about the treatment of an elderly patient are simply ignored by the mentor, leaving the student the choice of open revolt or beginning the task of internalizing a new value system. In this case, as in the vast majority, it is the

\section{equinoxonline}


latter course that is taken. Even senior health service managers, who come from a variety of backgrounds, articulate the importance of having strong shared values if working is to be successful and comfortable (Pattison and McKeown 2010). Where there is values dissonance, some felt strongly that they would have to move to a different organization and some, indeed, had done precisely this. While Pattison and McKeown (2010) question whether the values of NHS managers are quite as monolithic, unchanging and unequivocally beneficial as the managers themselves believed, there can be no doubt that many managers would implicitly see the inculcation of, and conformity to, strong public service values as vital in their subordinates. And insofar as newer, younger recruits to management and healthcare professions seem to be at odds with traditional espoused and enacted values, many healthcare professionals will informally express discomfort.

The emotional vulnerability of users of healthcare services will always provide professionals with opportunities for influence and even manipulation. Sarangi (2010) uses discourse analysis to illustrate the ways in which genetic counsellors on occasion attempt to shape the reflections and decisions of service-users. Such cases emphasize the importance that professionals' personal values can have in healthcare delivery; they remind us, too, of the likely gap between espoused professional values (such as 'non-directiveness') and actual values in practice. Thus, for example, NHS managers habitually espouse and enunciate the health and public service values of focusing on users and improving their experience both as individuals and collectivities and improving health outcomes. Yet it is often these same managers who obey political masters and imperatives, thus focusing away from users and often having to deprive them of services and improved health outcomes due to their pursuit and espousal in practice of the values of effectiveness, efficiency and economy (Pattison and McKeown 2010). This is not so much to level an accusation of hypocrisy as to point out that values compete for prominence and implementation so that people's highest and most visionary, altruistic values may not, in fact, be the ones that are enacted in practice. Pragmatism may thus be seen to temper idealism at all levels of values-talk and implementation in the NHS.

For someone with these kinds of views, changes in the NHS have to be judged according to whether they support or hinder a value-laden notion of caring, a view shared by professionals who may not subscribe to Cohen's (1999) theoretical framework (Hockley 2010; Sellman 2010).
Having the 'right' values, values that fit in with the spirit of the age and of the organization, is fundamentally important in the quest to retain trust and confidence in healthcare professions, now as much as at any time in the past. Indeed, the stakes are higher as government and management seek to gain value for money as well as more effectiveness and efficiency. Self-serving professions with values that only flatter the importance of their members are unlikely to be popular or successful here, so the assertion of values and identity is a delicate matter that has costs in terms of influence and reward if they do not contribute to an effective bid for professional credibility. Even chaplains and managers must be signed on to the 'right' professional and organizational values if their presence is to be welcomed or even tolerated in healthcare.

\section{Conclusion}

The rise and continuing importance of values-talk in the contemporary NHS is a phenomenon that, if nothing else, draws attention to the profound changes that are taking place in this organization and to the professions and professionals who must deliver its services. Values-talk can be seen as epiphenomenal verbiage, all talk with no implications for action. However, we hope we have shown that thinking seriously about how, why, where and when it happens, and who is engaged or disengaged in discussion, is powerfully symptomatic of important research issues about negotiation, power and identity. To see where values-talk is occurring and then to enquire into its significance in the NHS is better to understand the organization, its workers and its users. And this is of huge importance if the organization in its sum and constituent parts is to continue to command the interest and support of those who work in, provide and use it. Values-talk might, then, to paraphrase and parody Freud, be a royal road to understanding something of the lived consciousness and narrative of the NHS and contemporary professionalism as both come to terms with the increasing pace of change and development to which they have to respond.

\section{References}

Badcott, D. (2010). The profession of pharmacy in the United Kingdom: Changing values? In S. Pattison, B. Hannigan, R. Pill and H. Thomas (eds) Emerging Values in Health Care, 145-159. London: Jessica Kingsley Publishing.

\section{equinoxonline}


Ballard, P. (2010). The chaplain's dilemma. In S. Pattison, B. Hannigan, R. Pill and H. Thomas (eds) Emerging Values in Health Care, 187-202. London: Jessica Kingsley Publishing.

Cohen, M. (1999). A psychoanalytic view of the notion of integrity. In A. Montefiore and D. Vines (eds) Integrity in the Public and Private Domains, 88-108. London: Routledge.

Department of Health (2006). From Values to Action: The Chief Nursing Officer's Review of Mental Health Nursing. London: Department of Health.

Department of Health (2009). The NHS Constitution for England. London: Department of Health.

Edgar, A. (2010) Why do changes in society and institutions matter for professional values? In S. Pattison, B. Hannigan, R. Pill and H. Thomas (eds) Emerging Values in Health Care, 43-59. London: Jessica Kingsley Publishing.

Freidson, E.(2001). Professionalism: The Third Logic. Cambridge: Polity Press.

Hannigan, B. (2010). Values and mental health nursing. In S. Pattison, B. Hannigan, R. Pill and H. Thomas (eds) Emerging Values in Health Care, 109-127. London: Jessica Kingsley Publishing.

Hockley, C. (2010). Response [to Sellman 2010]. In S. Pattison, B. Hannigan, R. Pill and H. Thomas (eds) Emerging Values in Health Care, 141-143. London: Jessica Kingsley Publishing.

Hoggett, P., Mayo, M. and Miller, C. (2009). The Dilemmas of Development Work: Ethical Challenges in Regeneration. Bristol: Policy Press.

Johnson, T. (1972). Professions and Power. London: Macmillan.

Klein, R. (2007). Values talk in the (English) NHS. In S. Greer and D. Rowland (eds) Devolving Policy, Diverging Values: The Values of the United Kingdom's National Health Services, 19-28. London: The Nuffield Trust.

Laing, A., Newholm, T. and Hogg, G. (2005a). Crisis of confidence: Re-narrating the consumer-professional discourse. Advances in Consumer Research 32: 514-521.

Laing, A., Hogg, G. and Winkelman, D. (2005b). The impact of the internet on professional relationships: The case of healthcare. Service Industries Journal 25 (5): 675-687. doi:10.1080/02642060500101021

Monrouxe, L. and Sweeney, K. (2010). Contesting narratives: Medical professional identity formation amidst changing values. In S. Pattison, B. Hannigan, R. Pill and H. Thomas (eds) Emerging Values in Health Care, 61-78. London: Jessica Kingsley Publishing.

Newholm, T., Laing, A. and Hogg G. (2006). Assumed empowerment: Consuming professional services in the knowledge economy. European Journal of Marketing 40 (9/10): 994-1012. doi:10.1108/03090560610680970

Pattison, S. and McKeown, J. (2010). What are the values of NHS managers, and how have they changed since 1983? In S. Pattison, B. Hannigan, R. Pill and H. Thomas (eds) Emerging Values in Health Care, 209-225. London: Jessica Kingsley Publishing.
Pattison, S., Hannigan, B., Pill, R. and Thomas, H. (eds) (2010). Emerging Values in Health Care. London: Jessica Kingsley Publishing.

Pill, R. (2010). General practitioners and their values in a late modern world. In S. Pattison, B. Hannigan, R. Pill and H. Thomas (eds) Emerging Values in Health Care, 85-102. London: Jessica Kingsley Publishing.

Royal Pharmaceutical Society of Great Britain (2007). Code of Ethics for Pharmacists and Pharmacy Technicians. London: Royal Pharmaceutical Society of Great Britain.

Sarangi, S. (2010). Professional values in interaction: Nondirectiveness, client-centredness and other-orientation in genetic counselling. In S. Patterson, B. Hannigan, R. Pill and H. Thomas (eds) Emerging Values in Health Care, 163-180. London: Jessica Kingsley Publishing.

Sellman, D. (2010). Values and adult general nursing. In S. Pattison, B. Hannigan, R. Pill and H. Thomas (eds) Emerging Values in Health Care, 129-141. London: Jessica Kingsley Publishing.

Swift, C. (2010). Response [to Ballard, 2010]. In S. Pattison, B. Hannigan, R. Pill and H. Thomas (eds) Emerging Values in Health Care, 203-207. London: Jessica Kingsley Publishing.

Thomas, H. (1987). Machan on professional ethics. Philosophia 17 (1): 83-85. doi:10.1007/BF02390004

Huw Thomas received his PhD for work on 'race' and urban planning and is a Reader in Cardiff University. His current research interests are: urban planning practice, the planning profession, research ethics and the university as a site for vocational education. He has published on these matters over recent years in journals such as Planning Theory and Planning Theory and Practice. He is writing a book with the working title of Reading Plans. Address for correspondence: School of City and Regional Planning, Cardiff University, Glamorgan Building, King Edward VII Avenue, Cardiff CF14 1NW, UK. Email: ThomasH1@ cardiff.ac.uk

Stephen Pattison, HG Wood Professor of Theology and Professor of Religion, Ethics, and Practice at University of Birmingham, received his D.Litt. for work on pastoral and practical theology. His current research interests include values in professional practice, sensuality and visuality in religion and ethics and medical humanities. He has published in Journal of Medical Ethics, Medical Humanities and Practical Theology and has also written monographs on Shame and Seeing Things. He is currently writing a book on enfacement and shame. Address for correspondence: School of Philosophy and Theology, University of Birmingham, Edgbaston, Birmingham B15 2TT, UK. Email: S.Pattison.1@bham.ac.uk

\section{equinoxonline}

